\title{
AKULTURASI BUDAYA DAN AGAMA DALAM TRADISI KEKEBA/NGUPATI (SYUKURAN EMPAT BULAN) IBU HAMIL DI DESA PARAKANMANGGU PARIGI PANGANDARAN
}

\author{
Ai Adah Rahmani ${ }^{1}$, Dety Mulyanti ${ }^{2}$ \\ ${ }^{1,2}$ Universitas Sangga Buana YPKP Bandung \\ ${ }^{1}$ korespondensi : aiadahrahmani@gmail.com
}

\begin{abstract}
The Indonesian state consists of various kinds of customs and cultures, or it can be said that Indonesia is a multicultural country. The cultural diversity produces different habits in a place. When one culture with another culture mixes or meets then it is called cultural acculturation. The process of acculturation is not only between cultures, cultures and religions also experience acculturation. An example of cultural and religious acculturation activities in Parakanmanggu Village, Parigi Pangandaran, is the kekeba/ngupati (four month gratitude) tradition of pregnant women. The purpose of this study was to find out and examine the acculturation of culture and religion in the traditional activities of kekeba/ngupati (four month thanksgiving) for pregnant women in Parakanmanggu village, Parigi Pangandaran. The method used is descriptive qualitative with triangulation data collection techniques (observations, interviews, documentation). The results of the research that the kekeba/ngupati tradition in Parakanmanggu Parigi Pangandaran Village is an acculturation of local religion and culture, but in practice it is still carried out according to the teachings of the Prophet Muhammad SAW and there are no activities that are contrary to Islam
\end{abstract}

Keywords: Acculturation, culture and religion, kekeba/ngupati

\begin{abstract}
ABSTRAK
Negara Indonesia terdiri dari berbagai macam adat istiadat dan budaya, atau bisa dikatakan Indonesia merupakan Negara multicultre. Keberagamaan budaya tersebut menghasilkan kebisaan-kebiasaan yang berbeda di suatu tempat. Ketika budaya satu dengan budaya lainnya bercampur atau bertemu maka hal tersebut dinamakan akulturasi budaya. Proses terjadinya akulturasi bukan hanya antar budaya saja, budaya dan agamapun mengalami akulturasi. Adapun contoh kegiatan akulturasi budaya dan agama di Desa Parakanmanggu Parigi Pangandaran adalah tradisi kekeba/ngupati (syukuran empat bulan) ibu hamil. Tujuan penelitian ini adalah mencari tahun dan mengkaji akulturasi budaya dan agama dalam kegiatan tradisi kekeba/ngupati (syukuran empat bulan) ibu hamil di Desa Parakanmanggu Parigi Pangandaran. Metode yang digunakan adalah Kualitatif deskriftif dengan teknik pengumpulan data trianggulasi (observasi, wawancara, dokumentasi). Hasil penelitian bahwa tradisi kekeba/ngupati di Desa Parakanmanggu Parigi Pangandaran merupakan akulturasi agama dan budaya setempat, namun dalam pelaksanaannya tetap dilakukan sesuai dengan ajaran Nabi Muhammad SAW dan tidak ada kegiatan-kegiatan yang bertentangan dengan Agama Islam.
\end{abstract}

Kata kunci: Akulturasi, budaya dan agama, kekeba/ngupati

\section{PENDAHULUAN}

Indonesia merupakan Negara multikultur yang terdiri dari keberagaman suku, adat, dan budaya. Daerah atau tempat yang didiami komunitas masyarakat tertentu memiliki kebiasaan atau budaya yang berbeda satu sama lainnya. Ketika suatu komunitas masyarakat yang saling bersinggungan satu sama lain, maka akan menimbulkan percampuran budaya. Percampuran atau perpaduan budaya tersebut dinamakan akulturasi budaya. Dalam penelitian terdahulu akulturasi adalah pengambilan atau penerimaan satu atau beberapa unsur kebudayaan yang berasal dari pertemuan dua 
atau beberapa unsur kebudayaan yang saling berhubungan atau saling bertemu [1].

Kebudayaan menunjukan ciri kepribadian kelompok masyarakat dalam menjalankan kehidupan kesehariannya. Budaya merupakan implementasi pemikiran kelompok masyarakat tertentu. Kata budaya berasal dari kata budi dan daya, budi berarti akal, kecerdikan, kepintaran dan kebijaksanaan, sedangkan daya memiliki arti ikhtiar, usaha atau muslihat. Tradisi merupakan bagian dari budaya [2]. Dalam Kamus Umum Bahasa Indonesia tradisi memiliki makna segala sesuatu (seperti adat, kepercayaan, kebiasaan, ajaran) yang turun temurun dari nenek moyang [3].

Islam merupakan agama terbesar di Indonesia, mayoritas masyarakat Indonesia adalah pemeluk Islam. Ajaran agama Islam masuk ke Indonesia salah satunya dibawa oleh para pedagang Guzarat dari Jazirah Arab. Pesisir-pesisir Indonesia merupakan tempat pertama yang menerima ajaran Agama Islam, dikarenakan tempat tersebut merupakan tempat beristirahat para pedagang Guzarat. Islam diperkenalkan secara perlahan ketika proses transaksi jual beli yang dilakukan oleh pedagang Guzarat dan penduduk pribumi terjadi. Selain dengan cara perdagangan, penyebaran Islam di Indonesia dilakukan dengan cara pernikahan, pendidikan dan kesenian [4].

Para wali (wali songo) yang menyebarkan Syiar Islam di pelataran pulau Jawa salah satunya menggunakan media wayang. Wali songo mengemban tugas begitu berat dalam menyebarkan agama Islam di pelataran pulau
Jawa dikarenakan mayoritas penduduk pulau Jawa saat itu adalah Hindu. Diketahui bersama bahwa agama Hindu memiliki tradisi-tradisi yang syarat makna dalam proses menjalankan kehidupan kesehariannya. Para wali yang terdiri Sembilan orang tersebut menyebarkan agama Islam ke daerah yang berbeda. Lima diantaranya menyebar agama Islam di Jawa bagian timur, tiga diantara mereka menyebar agama di Jawa bagian tengah, dan satu lagi menyebar agama Islam di Jawa bagian barat [4].

Dalam proses penyebaran agama Islam yang diuraikan di atas, maka secara tidak langsung akan timbul adanya akulturasi budaya dan agama. Akulturasi tersebut terjadi karena adanya perpaduan antara budaya masyarakat pribumi sebelumnya dengan agama yang disebarkan yaitu agama Islam. Masyarakat yang berbudaya, dimana kebudayaan itu sendiri terlahir dari akibat adanya gagasan yang dihasilkan oleh pola fikir manusia yang dilakukan secara berulang dan turun temurun, maka masyarakat itu sendiri tidak akan mudah menerima hal baru dan meninggalkan kebiasaan lamanya. Alasan tersebut yang menimbulkan terjadinya akulturasi budaya dan agama.

Adanya akulturasi budaya dan agama merupakan keunikan dari corak keberagamaan yang ada dari tengah-tengah masyarakat [5]. Karena sebagai masyarakat yang sudah memiliki kepercayaan atau keyakinan sebelum Islam datang, maka nilainilai atau budaya sebelumnya masih melekat dalam keseharian mereka yang berakibat 
praktek keagamaan selalu kental dengan budaya yang telah lama ada.

Pangandaran merupakan salah satu daerah yang masyarakatnya terdiri dari suku sunda dan jawa. Kedua suku tersebut hidup saling berdampingan dengan tradisi yang sudah terakulturasi. Hal tersebut menjadikan tradisi suku sunda dan jawa di Pangandaran tidak memiliki perbedaan yang signifikan. Salah satu tradisi yang terakulturasi budaya dan agama adalah selametan, salah satunya yaitu selametan empat bulan kehamilan seorang ibu yang disebut dengan "kekeba/ngapati". Tradisi tersebut dilakukan sebagai ungkapan bentuk syukur kepada Allah SWT atas adanya janin yang dikandung oleh sang Ibu. Pada mulanya tradisi kekeba/ngupati di Pangandaran dilakukan dengan berbagai acara dan ritual yang syarat makna serta dianggap bertentangan dengan ajaran Islam. Masyarakat Pangandaran pada saat itu masih mempercayai terhadap hal atau kegiatan yang bersifat mistis dan tabu.

Seiring dengan berkembangnya zaman serta Ilmu Pengetahuan dan Teknologi (IPTEK), tradisi kekeba/ngupati di Pangandaran mulai mengalami perubahan dalam pelaksanaannya. Sedikit demi sedikit kegiatan atau acara yang dilakukan dalam tradisi kekeba tidak dihiasi dengan hal yang mistis, saat ini kegiatan tersebut hanya diisi dengan pengajian dan acara makan bersama dengan saudara, kerabat dan tetangga.

Perubahan yang terjadi pada tradisi kekeba/ngupati di Panandaran menjadikan sebuah kajian yang menarik bagi penulis untuk mengetahui apa alasan yang menyebabkan terjadinya perubahan pada komposisi kegiatan tradisi kekeba/ngupati? Terkait permasalahan tersebut penulis melakukan wawancara langsung dengann salah satu tokoh masyarakat di desa Parakan Manggu, kecamatan Parigi kabupaten Pangandaran. Tokoh tersebut merupakan ketua MUI desa Parakan Manggu yaitu Ajengan Otong, masyarakat setempat memanggilnya dengan sapaan Kang Otong

\section{TINJAUAN PUSTAKA}

Sejarah awal mula adanya tradisi selametan yang dilakukan pada ibu hamil dijelaskan dalam kajian terdahulu yang berjudul Neloni, Mitoni atau Tingkeban, yaitu awal mula adanya tradisi selametan bermula dari cerita rakyat pada zaman dahulu dikisahkan bahwa ada wanita yang bernama Niken Satingkeb yang menikah dengan pemuda yang bernama Sadiyo [6]. Dari hasil pernikahan mereka dikaruniai sembilan orang anak. Nasib yang baik tidak menyertai pernikahan mereka, karena kesembilan anak mereka tidak ada yang hidup lama, semua anak mereka meninggal dunia. Dengan kejadian pilu tersebut mereka tidak putus asa dan menyerah, mereka tetap berusaha dengan do'a dan ikhtiar. Segala bentuk petuah dan saran yang diberikan kerabat serta keluarga dijalankannya, namun tetap tidak membuahkann hasil.

Suatu hari nyai Niken Satingkeb dan suaminya menghadap Raja Jayabayan dan menceritakan kejadian pilu yang dialami mereka. Sang raja merasa prihatin dan haru atas cerita yang mereka paparkan. Maksud 
kedatangan Niken dan Sadiyo menghadap sang raja adalah untuk meminta petuah serta petunjuk hal apa yang harus mereka lakukan agar mereka dikaruniai keturunan kembali dan berumur panjang. Raja Jayabaya menyarankan kepada nyai Niken Satingkeb agar mandi setiap hari Rabu dan Sabtu menggunakan gayung yang terbuat dari tempurung kelapa (bathok). Setelah mandi, Niken diharuskan memakai pakaian yang bersih kemudian dijatuhkan dua kelapa gading antara perut dan pakaian.

Niken Satingkeb melakukan segala petunjuk yang dianjurkan oleh raja Jayabayan, ternyata harapan sepasang suami istri tersebut dikabulkan. Mereka dikaruniai anak kembali. Semenjak itu upacara tersebut dilakukan secara berulang dan turun temurun oleh masyarakat.

Tradisi kekeba/ngupati merupakan kegiatan sebagai upaya bentuk syukur kepada sang pencipta atas dianugrahinya janin di dalam rahim sang ibu. Kekeba/ngupati merupakan upacara atau selametan yang diadakan oleh komunitas masyarakat untuk memperingati keberadaan janin yang dikandung ketika memasuki usia empat bulan [5].

Dalam pelaksanaan tradisi kekeba/ngupati, sohibul bait (tuan rumah) melakukan permohonan keselamatan, keberkahan dan kesejateraan sang calon bayi. Oleh karena itu dibacakan surat-surat Al-Quran seperti surat Yusuf, dimaksudkan agar calon anaknya kelak memiliki paras seperti Nabi Yusuf a.s., selanjutnya surat Maryam, pembacaan surat ini diharapkan ketika sang calon bayi memiliki sifat dan kepribadian seperti Siti
Maryam. Surat Al-ikhlas, Al-Falaq, An-Nas, dan Yasin, diharapkan anaknya kelak memiliki tauhid agama yang kuat. Terakhir Surat Ar-Rahman, diharapkan agar sang anak kelak memiliki sifat serta sikap penyayang terhadap keluarga, saudara, sesama dan alam semesta [5],

Ada beberapa bentuk selametan yang dilakukan oleh ibu hamil [1] sebagai berikut:

a. Selametan Kehamilan pada Bulan Kedua

Saat seorang wanita mengalami hamil pada kali pertama maka diadakan selametan kehamilan diusia dua bulan, adapun perlengkapan yang perlu disediakan adalah sebagai berikut:

1) Nasi Sayuran, yaitu nasi tumpeng beserta sayuran dengan hitungan ganjil, seperti $3,5,7$ dan seterusnya.

2) Jenang putih, yaitu jenang berwarna putih yang terbuat dari campuran tepung beras dan santan kelapa.

3) Jenang merah, yaitu jenang yang terbuat dari beras yang dicampur dengan santan dan gula merah.

4) Jenang merah putih, yaitu perpaduan jenang warna merah dan warna putih.

5) Jenangg boro-boro/jenang katul, yaitu jenang yang terbuat dari kulit ari beras yang lembut serta berwarna cokelat, lalu diberi taburan gula kelapa dan parutan kelapa. 
6) Jajanan pasar dan buah-buahan, jajanan pasar bisa berupa wajit, jadah, jenil, lapis, dan onde-onde.

\section{b. Selametan Kehamilan pada Bulan} Keempat.

Selametan bulan keempat atau yang disebut kekeba/ngupati perlengkapan yang dipersiapkan dalah sebagai berikut:

1) Nasi uduk, yaitu nasi yang berwarna kuning yang dicampur dengan kunyit yang dihidangkan dengan sambel serta lauk-pauk tertentu.

2) Kue apem, yaitu kue yang terbuat dari beras yang diberi ragi dan gula kelapa.

3) Ketupat.

c. Selametan Kehamilan pada Bulan Ketujuh.

Selametan pada usia kandungan ketujuh disebut dengan istilah mitoni, adapun pelaksanaan kegiatannya adalah sebagai berikut:

1) Siraman.

2) Memasukan telur ayam ke dalam sarung yang dipakai calon ibu.

3) Calon ibu mengganti pakaian sebanyak tujuh kali.

4) Calon nenek dari pihak wanita menggendong kelapa gading yang diteroboskan lewat kain menuju bawah.

d. Selametan Kehamilan pada Bulan Kesembilan. Menjelang kelahiran bayi dilakukan selametan jenang procot pada usia kandungan Sembilan bulan. Upacara ini bertujuan agar bayi yang dilahirkan sehat dan tidak memiliki kekurangan apapun. Jenang procot merupakan jenang yang terbuat dari tepung beras yang diberi cairan gula kelapa dan pisang raja yang telah dikupas kulitnya.

\section{METODE}

Metode yang digunakan dalam penelitian ini adalah kualitatif deskriptif. Metode penelitian merupakan cara ilmiah dalam suatu penelitian berdasarkan tujuan dan kegunaan tertentu untuk memperoleh data [7].

Metode penelitian kualitatif merupakan metode yang digunakan untuk meneliti suatu obyek atau peristiwa dimana peneliti merupakan instrumen kunci dari penelitian, teknik pengumpulan data dilakukan dengan cara trianggulasi (observasi, wawancara, dokumentasi), data yang diperoleh merupakan data kualitatif dan hasil dari penelitian bersifat temuan, keunikan objek, makna suatu peristiwa, fenomena, proses dan interaksi sosial [7]

Teknik Pengumpulan data dalam penelitian ini menggunakan teknik trianggulasi. Trianggulasi merupakan teknik pengumpulan data yang bersifat menggabungkan beberapa teknik pengumpulan data dan sumber data yang telah ada[8].

1. Observasi

Observasi merupakan kegiatan pengumpulan data dengan cara datang dan mengamati secara langsung ke tempat atau objek yang akan diteliti. Pada kegiatan ini peneliti dapat 
mengumpulkan data-data sekunder yang diperoleh di lapangan.

2. Wawancara

Wawancara adalah teknik pengumpulan data dengan cara melakukan wawancara secara langsung dengan narasumber [9]. Pada kegiatan ini penulis bisa merekam audio atau visual dalam bentuk video.

3. Dokumentasi
Dokumentasi merupakan teknik
pengumpulan data dengan cara pengmbilan gambar objek penelitian.

Pada penelitian ini penulis menentukan narasumber penelitian berdasarkan permasalahan penelitian yang diteliti. Adapun yang menjadi narasumber penelitian adalah Kang Otong selaku Ketua MUI Desa Parakanmanggu Parigi Pangandaran. Berikut biodata lengkap Kang Otong:

Tabel 1 : Biodata Ketua MUI Desa Prakanmanggu Parigi Pangandaran

\begin{tabular}{|c|c|c|c|}
\hline Nama & Tanggal Lahir & Jabatan & Periode \\
\hline Otong Tojani & 15 Maret 1957 & Ketua MUI Desa Parakanmanggu & 2006-sekarang \\
\hline
\end{tabular}

\section{HASIL DAN PEMBAHASAN}

Tradisi Kekeba/Ngupati di desa Parakan Manggu kecamatan Parigi kabupaten Pangandaran

Berdasarkan data yang penulis dapatkan dari hasil wawancara dengan Kang Otong, bahwa tradisi kekeba/ngapati di desa Parakanmanggu mengalami perubahan komposisi dalam kegiatannya. Tradisi ini tidak serumit yang dipaparkan oleh teori/literatur yang ada. Jika pada literatur-literatur yang penulis nukil bahwa tradisi kekeba/ngapati harus mempersiapkan perlengkapan dan sajian sebagai simbol. Kang Otong memaparkan bahwa hal tersebut termasuk Bid'ah Dhalalah (Kebiasaan yang tidak dilakukan pada zaman Nabi dan bersifat menyalahi AlQuran) jika mempercayai peralatan tersebut akan mendatangkan kebaikan dan pertolongan. Karena sejatinya pengharapan manusia hanya bersandar pada pertolongan Allah SWT.

kekeba/ngupati

Parakanmanggu sama sekali tidak menggunakan peralatan yang dipaparkan dalam teori. Untuk sajian atau makanan pun tidak diwajibkan keberadaannya jika sohibul bait merasa tidak mampu atau tidak memiliki materi yang cukup untuk diadakan. Namun jika sohibul bait merasa mampu menyediakan maka tidak ditentukan spesifikasi makanan yang harus disajikan seperti yang dijelaskan dalam teori. Penyajian makanan tersebut ditujukan atau diniatkan untuk bersedekah terhadap sesama umat Islam. Sejatinya acara inti diadakannya tradisi kekeba/ngupati sebagai bentuk rasa 
syukur seorang hamba kepada sang Pencipta atas dikaruniakannya janin pada rahim calon ibu. Maka dari itu kegiatan tersebut diisi dengan pembacaan surat-surat dalam Al-Quran dan pemanjatan do'a-do'a.

Adapun runtutan acara tradisi kekeba/ngupati di desa Parakan Manggu adalah sebagai berikut:

a. Sohibul bait melakukan nyorog kepada para ulama serta tokoh masyarakat setempat. Nyorog adalah memberikan makanan berupa nasi dengan lauk-pauk seadanya yang diberikan oleh sohibul bait. Nyorogg bertujuan untuk bersedekah, oleh karena itu tidak diwajibkan jika sohibul baik merasa tidak mampu.

b. Mengundang saudara, kerabat, masyarakat atau tetangga setempat untuk menghadiri acara kekeba/ngupati. Hal tersebut bertujuan untuk menyambung tali silaturahmi dengan mereka.

c. Membaca surat-surat dalam AlQuran sebagai bentuk panjatan do'a terhadap Allah SWT. Surat-surat AlQuran yang dibacakan diantaranya:

1) Surat Yusuf, dengan dilantunkannya surat Yusuf diharapkan ketika kelak bayi lahir ke dunia bisa memiliki ketampanan seperti Nabi Yusuf a.s.
2) Surat Maryam, berharap ketika sang bayi lahir akan memiliki sifat dan perangai seperti Siti Maryam.

3) Surat Al-Ikhlas, Al-Falak, An-Nas, Al-Kahfi dan Yasin, diharapakan bayi yang lahir nanti akan memiliki tauhid agama yang kuat.

b. Kegiatan akhir pada tradisi kekeba/ngapati adalah makan bersama tamu undangan dengan tujuan berbagi nikmat dan sedekah.

Ada sekelumit penasaran yang menggelayut di hati penulis yang pada akhirnya penulis tanyakan kepada Kang Otong, yaitu "Mengapa tradisi kekeba/ngupati dilakukan pada bulan keemapat kehamilan?" Kang Otong memaparkan jawaban atas pertanyaan penulis tersebut bahwa alasan dilakukannya tradisi kekeba/ngupati pada bulan keempat adalah pada bulan tersebut Allah melalui malaikat Jibril meniupkan ruh pada bayi yang dikandung sang ibu. Dari situlah dimulainya kehidupan sang bayi di dalam rahim ibu.

Pernyataan Kang Otong mengenai ditiupkannya roh pada sang bayi dijelaskan dalam hadist Nabi Saw., yang diriwayatkan oleh Al-Bukhori, Muslim, Al-Tirmizi, Abu Dawud dan Ahmad bin Hambal dalam penelitian yang dilakukan Su'aidi [5] sebagai berikut: 
Dari Hasan bin Rabi' dari Abu AlAhwash dari dari A'masy dari Zaid bin Wahab, Abdullah (yaitu Abdullah bin Masudd ra) berkata: Rosulullah Saw..sebagai manusia yang benar dan dibenarkan bersabda: Sungguh seorang dari kalian dihimpun dari air mani (penciptaan)Nya di dalam perut ibunya selama empat puluh hari sebagai seperma, lalu empat puluh hari kemudian berwujud segumpal darah, lalu berwujud sekerat daging selama empat puluh hari, kemudian malaikat (pengutus ruh) diutus, maka ditiupkan ruh padanya (setelah usia kandungan 120 hari), dan malaikat itu diperintah untuk mencatat empat ketentuan, ditentukan rizkinya, ajal (masa hidup) nya, perilaku-perilakunya, dan sebagai orang yang celaka atau sebagai orang yang beruntung. Demi Allah yang tiada Tuhan selain Dia, sungguh seorang dari kalian akan selalu berbuat perbuatan penduduk syurga, hingga seukur, sehasta anatar ia dan syurga, lalu ia didahului ketentuan (yang tertulis ketika ia berada di dalam perut ibu) maka ia berbuat perbuatan penduduk neraka, maka masuklah ia ke dalam neraka. Dan sungguh seorang dari kalian selalu berbuat perbuatan penduduk neraka, hingga antara ia dan neraka seukur sehasta, lalu ia (menjelang kematian) didahului ketentuan takdir maka ia berbuat perbuatan penduduk syurga, maka masuklah ia ke dalam syurga. (H.R. Al-Bukhari dan Muslim).

Selain menukil dari hadist tersebut, proses pembentukan janin dalam rahim seorang ibu dijelaskan dalam Quran Surat Almu'minun ayat 12-14 yang artinya sebagai berikut[10]:

"Dan sesungguhnya kami telah menciptakan manusia dari suatu sari pati (berasal) dari tanah. Kemudian Kami jadikan sari pati itu menjadi air mani (yang disimpan) dalam tempat yang kokoh (rahim). Kemudian air mani itu Kami jadikan segumpal darah, lalu segumpal darah itu Kami jadikan segumpal daging, dan segumpal daging itu Kami jadikan tulang belulang, lalu tulang belulang itu kami bungkus dengan daging. Kemudian kami jadikan mahluk yang (berbentuk) lain. Maka maha suci Allah pencipta yang baik."

Kang Otong menjelaskan dengan lugas bahwa tidak ada satupun dalil atau hadist yang mewajibkan dilaksanakannya tradisi kekeba/ngupati dan hal tersebut pun tidak termasuk sunah Nabi. Namun pada hakekatnya Nabi Muhammad Saw selalu mengajarkan kebaiakan seperti bersedekah, melakukan silaturahmi, dan berdo'a. Maka dari itu beliau menegaskan bahwa tradisi kekeba/ngupati diperbolehkan selama dalam kegiatan terebut tidak mengandung 
unsur yang bertentangan dengan ajaran Islam.

Alasan yang Mempengaruhi Perubahan Komposisi Kegiatan Tradisi kekeba/ngupati di Desa Parakan Manggu.

Sebelumnya tradisi kekeba/ngapati di daerah Pangndaran dihiasi dengan ritual dan penyajian makanan tertentu yang dianggap sangat berpengaruh terhadap kehidupan bayi yang sudah lahir dikemudian hari, namun hal tersebut tidak lagi disertakan. Adapaun alasan mengapa terjadi perubahan komposisi kegiatan tersebut adalah masyarakat setempat sudah mulai meyakini bahwa hal-hal tahayul atau benda yang dianggap akan memberikan kekuatan itu tidak ada. Nilai ketauhidan yang tertanam sudah semakin kuat karena banyaknya ulama yang memberikan pemahaman bahwa hal tersebut tidak ada dalamm dalil ataupun sunnah Nabi. Dan jika mempercayai hal tersebut bisa mengantarkan umat Muslim dalam kesesatan bahkan perbuatan Syirik (menyekutukan Allah).

\section{KESIMPULAN}

Tradisi kekeba/ngapati di daerah Pangandaran merupakan akulturasi budaya masyarakat dahulu dengan agama. Kekeba/ngupati merupakan kegiatan sebagai ungkapan syukur kepada sang Pencipta atas janin yang berada dalam rahim sang ibu. Berdasarkan hasil kajian penulis dari literatur-literatur yang berkaitan dengan permasalahan dan hasil wawancara penulis dengan Kang Otong selaku ketua MUI desa
Parakan Manggu. Bahwa dalam pelaksanaan tradisi tersebut tidak sesuai dengan pemaparan yang ada dalam teori.

Terjadi perubahan komposisi kegiatan dalam tradisi kekeba/ngapati di desa Parakan Manggu. Sebelumnya tradisi tersebut dihiasi dengan kebiasaan yang dinilai bertentangan dengan ajaran Islam berubah menjadi sebuah kegiatan yang didalamnya mengandung unsur kebaikan seperti sedekah, silaturahmi, dan berdoa.

Alasan ada perubahan komposisi dalam kegiatan kekeba/ngapati adalah tumbuhnya kesadaran dalam masyarakat bahwa jika melakukan ritual atau mempercayai suatu benda yang dianggap memberikan kekuatan serta pertolongan adalah perbuatan yang dilarang karena hal tersebut merupakan perbuatan syirik (menyekutukan Allah).

\section{DAFTAR PUSTAKA}

[1] M. Mustaqim, "Pergeseran Tradisi Mitoni: Persinggungan adtara Budaya dan Agama," Penelitian, vol. 11, no. 1, pp. 119-140, 2016.

[2] Buhori, "Islam dan Tradisi Lokal di Nusantara (Telaah Kritis terhadap Tradisi Pellet Betteng pada Masyarakat Madura dalam Perspektif Hukum Islam)," al-Maslahah, vol. 13, no. 2, pp. 229-2476, 2017.

[3] Kamus Umum Bahasa Indonesia Edisi Ke Tiga. Jakarta: Balai Pustaka, 2003.

[4] Safira and A. S. M. Daniel, "Tradisi Mapati dan Mitoni Masyarakat Jawa Islam," 2016. 
[5] H. Su'aidi, "Korelasi Tradisi Ngapati dengan Hadist Penciptaan Manusia," Religia, vol. 15, no. 1, pp. 88-106, 2016.

[6] Iswah Ardiana, "Neloni, Mitoni, atau Tingkeban (Perpaduan antara Tradisi Jawa dan Ritualitas Masyarakat Muslim)," karsa, vol. 19, no. 1, pp. 239-247, 2011.

[7] Sugiyono, Medote Penelitian Pendidikan. Bandung: Alfabeta, 2019.
[8] Sugiyono, Metode Penelitian Manajemen. Bandung: Alfabeta, 2017.

[9] Lexy J. Moleong, Metode Penelitian Kualitatif. Bandung: Rosda, 2011.

[10] Al-Quran dan Terjemahannya. Bandung: Cordoba Internasional Indonesia, 2012. 